\title{
MODIS data based Semi-Real Time Media GIS Contents to Support Natural Disaster Mitigation
}

\author{
${ }^{1}$ Kithsiri Perera and ${ }^{2}$ Ryutaro Tateishi \\ ${ }^{1}$ School of Civil Engineering and Surveying and International Centre for Applied Climate Sciences, \\ University of Southern Queensland, West Street, Toowoomba 4350 QLD Australia \\ ${ }^{2}$ Centre for Environmental Remote Sensing (CEReS), Chiba University, Japan
}

\begin{abstract}
Natural disaster mitigation is a collective effort of forecast, assessment, and encouraging the public participation in disaster mitigation. This study focused on the rarely addressed aspect, "the value of public awareness" in natural disaster mitigation. The methodology used satellite data and Geographic Information Systems (GIS) to produce semi-real-time "Media GIS" contents. When deliver the content to the media with maximizing four related factors; speed, attractiveness, richness, and accuracy, Media GIS contents will help to increase the public awareness on the respective disaster. The methodology to produce Media GIS contents is based on; basic fundamentals of GIS, freely available satellite images, and information extracted from Google Earth. Hence, contents carry inherent characters of GIS and significantly different from conventional graphics in media. Also the graphical variables like, size, value, texture, hue, orientation, and shape, were optimized to match with target content users (age group, social group) and medium (print, TV, WEB, mobile), while minimizing the cost. With the news brakes of the disaster, MODIS (250m) satellite data can be extracted in Geo TIFF and KLM (Keyhole Markup Language) formats. The KML file can be overlayed on Google Earth, to extract more spatial information of the area of interest. Photoshop or any similar graphic software can be used to create the product while keeping the geometric character of the content. The final output (in TIFF/JPEG and KLM file) is the GIS media content for TV, WEB, mobile contents, and for print media, which support to increase the public awareness of the disaster. Two cases studies; disastrous flood occurred in Bangkok in 2011 and the severe drought recorded in eastern Sri Lanka in 2014, are presented in the study.
\end{abstract}

KEYWORDS: Disaster mitigation, Media GIS, MODIS, NDVI, Semi real time, Public awareness 


\section{INTRODUCTION}

GIS (Geographic information systems) is a computer-based process to capture, maintain, store, analysis, and distribute spatial data and associate attributes (Nationmaster.com 2010). Application of GIS is increasingly becoming popular among scientists, from Geography to some applications in medical science. In the field of natural disaster application, GIS is one of the most powerful data handling approaches to support efficient decision making. For an example, a GIS program might be allowed emergency planners to calculate emergency response time in a natural disaster, or find wetlands that need protection from pollution (USGS Geography Publications, 2008). Apart from direct applications in natural disasters, GIS can be successfully used to widen the public awareness about natural disasters. This sub-division of GIS can be termed as Media GIS, which is capable of linking disaster news with location based semi-real-time information derived from satellite images. The prime object of the Media GIS contents is to widen the public awareness of natural disasters, in order to attract better involvements from the public to mitigate the damage. This study explains the conceptual base for production of high quality semi-real-time natural disaster graphic contents (image maps) for media GIS. Two case studies are also added to demonstrate the functionality of Media GIS content production.

Today, media contents give a tremendous impact on our daily life. Media, (the plural of "medium") a truncation of the term "media of communication," refers to dissemination of facts, opinions, entertainments, and other information, through newspapers, magazines, outdoor advertising, film, radio, television, the World Wide Web (WWW), books, CDs,
DVDs, videocassettes, computer games, and other forms of publishing (new world encyclopedia, 2008). Among various news items in media, reports related to natural disasters play a significant role, since natural disasters are directly related to people, economy, and environment. The victims of earthquakes, hurricanes, tsunamis, floods, and droughts are perceived as $100 \%$ blameless and get a bigger sympathy from the world, while the victims of wars do not enjoy such absolute status (Stroehlein, 2010). The requirement of immediate damage assessments and high speed relief assistances to the affected area can be linked with the resourceful media contents of the respective disaster. However, the lack of spatial information in these media reports makes a significant inadequacy in information aspect. One typical example, a news item from 2014 landslide disaster occurred in Sri Lanka is presented in figure 01 which has no graphical information about the location.

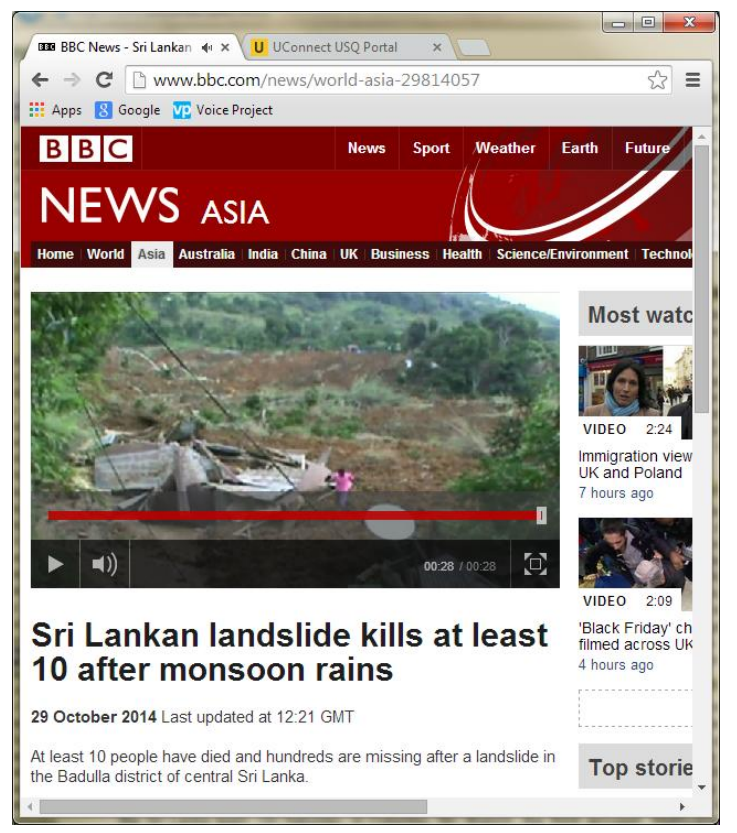

Figure 1. One of the recent natural disaster news items in BBC

(source:http://www.bbc.com/news/world-asia-

29814057, downloaded on 30 Nov 2014) 
There 100s of similar news items available around the world through the web and print media, but with a very limited use of spatial information. When news travels around the world at a lightning speed using satellite communication systems, it's beneficial for readers to have information about location and semi-real-time pictorial information of the disaster. In this regards, the application of satellite images, especially semi-real-time satellite images can be a very effective addition for media contents of natural disasters (USGS, 2011; Altan at el., 2010; Nakya et al., 2007, Perera and Pathirana, 2006). The use of the term "semi-real-time" in this report includes the time from acquisition of satellite images to end product of the disaster media content.

\section{MEDIA GIS AND IMAGE MAPS}

The power of GIS comes from its capability to relate different information (data) in a spatial context and to reach a conclusion about relationships among used data layers (USGS Geography Publications, 2008). Any natural disaster contains the location information or spatial character, which links to a certain location on the earth. As an example, when a flood disaster hit, it is important to know where the extreme rainfall was recorded, directions of flood flow, and affected infrastructures. In most of the cases, satellite images of flood incidents are fully covered with clouds, however, these could images are showing information about the degree of the rainfall. When the flood is prolonged, it's possible to obtain clearer images to show extent of flooded area, enabling to display first-hand information taken from the space. The involvement of satellite image-based Media GIS contents in the natural disaster reporting increases the commercial and information value of the news item. Figure 2 simplified this involvement with three possible scenarios, i.e., extensive, partial, and nonexistence of location based image contents.

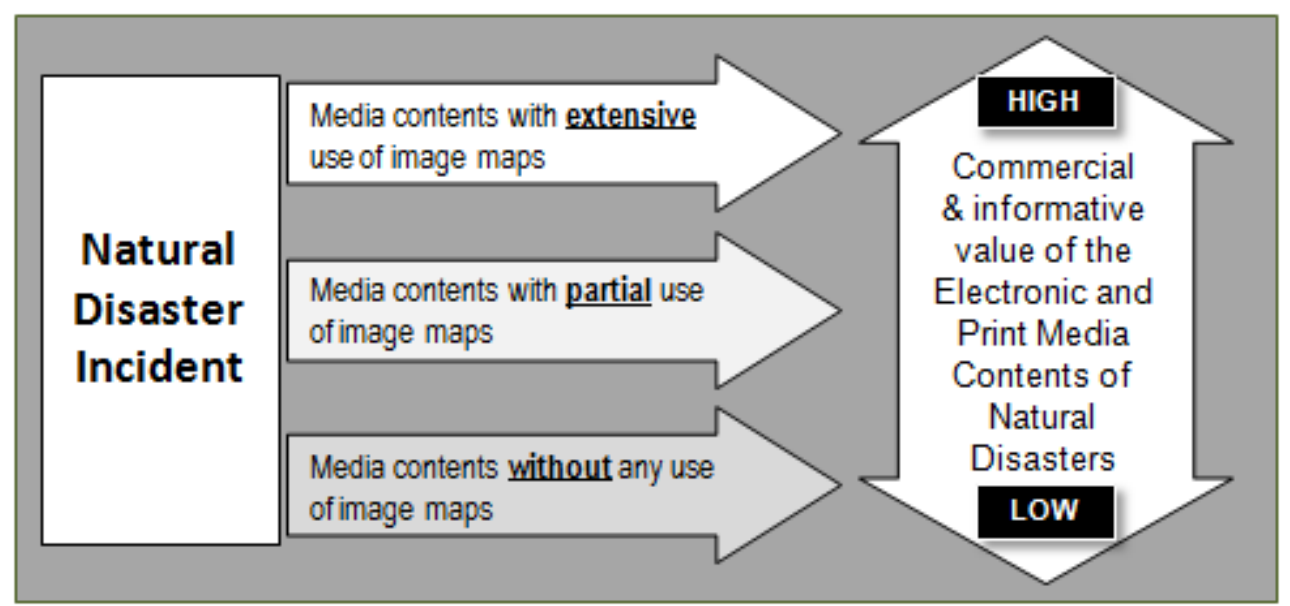

Figure 2. The value of natural disaster content can be upgraded through the use of image maps 
When the spatial character of the brake of a natural disaster news item. The natural disaster is transferred into the GIS database, a new set of application potentials emerges. This whole range of activities can be labeled as production of Media GIS contents, a sub-division of GIS. Media GIS contains number of basic GIS components as describes in Figure 3. According to the figure, Media GIS content starts with the content maker should search and collect relevant real-time and archived data of the incident. Content production and relay it to the customer or viewer through appropriate media platforms ends the process. In order to maximize the content value, the production process must maintain number of standards.

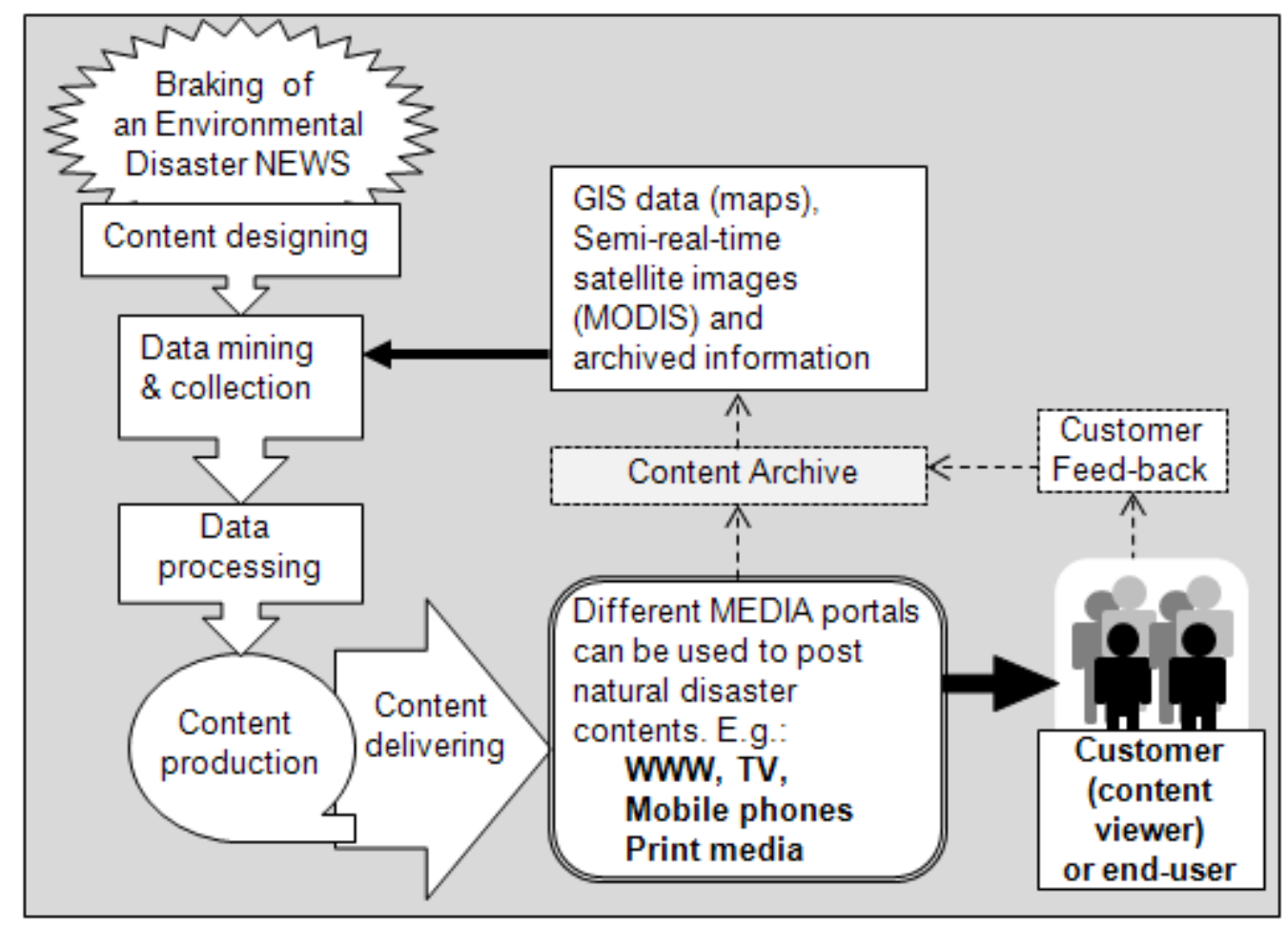

Figure 3. The simplified production flow of Media GIS

Image maps, the primary product of Media GIS, are geometrically registered satellite images or aerial photographs. They are extensively used in various situations, from private GIS users, academics, to large organizations like NASA to; present, and explore land surface information in greater details (Short, 2010; Sultan et al., 2008). Georectified image maps can be included into a
GIS system to conduct further analyses or present as a graphic content. The scientific base of image maps comes under the spatial data visualization. In spatial data visualization, there are three major objectives, i.e., data presenting, data analyzing, and data exploring (Kraak, 1999). Most of the Media GIS graphic contents "present" information and while some analyze or explore the incident further. 


\section{THE CONCEPT OF MEDIA GIS}

Media GIS explains in this report can be considered as a computer-based system that explore, collect, maintain, store, analyze, and distribute, graphic contents of natural disasters and other spatially located significant incidents to use in electronic and print media, with a high esthetic quality. Media GIS needs to produce image maps for media with a considerable academic authorization at semi-real-time phase. In operation, optimizing the main graphical variables such as, size, value, texture, hue, orientation, and shape, is vital when the Media GIS content prepared for media (print, TV, WEB, mobile), while minimizing the cost. Under the case study section, the presentation aspect will be visualized with multi-temporal (the GIS component) images maps of two natural disaster incidents. The goal of the Media GIS should enrich the user understanding about the incident and increase the awareness of the disaster, while improving the quality of media business. Here, Media GIS content production focuses on five basic standards, i.e.; accuracy, high esthetic quality, speed, low cost, and reusability (Perera and Tateishi, 2008). The content maker must have some level of basic knowledge in; GIS, remote sensing, and graphics, to maintain these standers.

\subsection{Accuracy}

Media GIS contents pass firsthand information to general public; therefore the geographical and informative accuracy of the contents is paramount. This accuracy can be maintained, when the content production is based on georectified image products such as MODIS (Moderate-resolution Imaging Spectroradiometer) satellite images.
Geographical accuracy is very important to merge other GIS data including archived data layers. However, if the media content plays bigger attention on informative accuracy, geographic registration may get a lesser importance.

\subsection{High Esthetic Quality}

The use of colors (hue), fonts (type, size, color, and orientation), and symbols in media graphics must be carefully selected to meet the technical capabilities and expectations of target age groups. Graphics should not hinder the original information in the image. Font sizes must be large enough to read easily and priorities of words on the content must be carefully balanced to maintain the visual quality. For web/mobile media, graphics must have smaller file size (JPG/GIF formats) to maximize the download time. For TV media, full color heavy TIF graphic products can be created, while maximizing the visual quality. All graphic products in original TIF format with all image layers must be systematically archived for future use. Tailoring graphics into various media platforms is not discussed in depth in this paper. Specially, web based data visualization and presenting methods face regular developments (Friedman, 2007; Ostrow, 2007). Therefore, the content producer must study new technological developments regularly.

\subsection{Production Speed}

Speed can be maximized at three different levels. The first is data mining, downloading, and converting into the GIS database. The second is graphic production process, which mainly controls in ArcGIS (or other GIS software), Photoshop (or other 
graphic software), and Google Earth environments. Here, skills and some experience in graphics as well as a basic knowledge in other software packages are necessary. Speed of the content production has a direct link with the commercial usage of the product. If the media company demands the contents without very high geographic accuracy, the content producer has to entertain such requests positively to balance the market/customer requirements. Thirdly, media contents must have the correct file size, image size, and file format to maximize the speed and support the data interoperability.

\subsection{Low Cost}

The use of freely available of MODIS satellite data and Google Images help to minimize the overall coast of Media GIS contents. Initial cost for ArcGIS will be a significant limitation, but producer can explore the applicability of functions in any other open source remote sensing and GIS software package which can be a substitute. Google Earth data, functions, and large number of supportive documents are freely available through the internet. Initial cost for Photoshop is relatively low compare to its excellent functionality in graphics. An older CS version of Photoshop is between US $\$ 350$ to US $\$ 650$ over the internet and strong enough to produce excellent graphics. Also there are free graphic software packages such as GIMP or Pixar with reasonable capabilities.

\subsection{Reusability}

All Media GIS contents need to be systematically archived. The final product as well as the interim products can be archived by topic, geographic region, and date. Some end- products can be reused without any additional change to display historic conditions. A proper archive system of contents and customer feedback (see figure 3) help to lower the overall production cost.

\section{DATA AND METHODOLOGY}

\section{1. MODIS Satellite Data}

MODIS provides very useful satellite images for a range of applications on earth surface and atmosphere (Friedl et al., 2002; Hall et al., 2003; Zhan et al., 2002). MODIS products such as MODIS NDVI (MODIS web, 2012; Perera and Tsuchiya, 2009; USGS, 2007) and true color imagery (MODIS web, 2012; NASA Rapid Response, 2014; Gumley et al., 2003) are freely available through NASA. MODIS has the capability to show at least some of the widespread disaster incidents within 24 hours of time span. The first time users should learn about MODIS sensor characteristics, temporal, and spectral resolutions, from the well-documented MODIS official web site (MODIS web, 2012). In this study, we have used these freely available pre-processed NASA's MODIS products to create Media GIS contents for 2 case studies. Figure 4 shows Southeast Asia MODIS sub-scene layout, which covers images used in the case studies. Table 1 has summarized the MODIS information with respect to Media GIS content production. 
Table 1. MODIS information useful for media contents (compiled from information available in MODIS sites)

\begin{tabular}{|c|c|}
\hline Element & Information \\
\hline Orbit & $\begin{array}{l}705 \mathrm{~km}, 10: 30 \text { a.m. descending node (Terra) or 1:30 p.m. ascending } \\
\text { node (Aqua), sun- synchronous, near-polar, circular }\end{array}$ \\
\hline Swath Dimensions & $2330 \mathrm{~km}$ (cross track) by $10 \mathrm{~km}$ (along track at nadir) \\
\hline Spatial Resolution & $250 \mathrm{~m}$ (bands 1-2), $500 \mathrm{~m}$ (bands 3-7), $1000 \mathrm{~m}$ (bands 8-36) \\
\hline $\begin{array}{l}\text { Available file (image) } \\
\text { formats }\end{array}$ & $\begin{array}{l}\text { Geo-TIFF, JPG, and KMZ (Keyhole Markup Language Zipped - file } \\
\text { format needed display on Google Earth). }\end{array}$ \\
\hline $\begin{array}{l}\text { Available ready to use } \\
\text { sub-scenes }\end{array}$ & $\begin{array}{l}\text { - Aerosol Robotic Network (AERONET) } \\
\text { - USDA Foreign Agricultural Service (FAS) (see figure 4) } \\
\text { - Fire Information for Resource Management System (FIRMS), } \\
\text { Antarctica, Arctic, Other }\end{array}$ \\
\hline Available image products & $\begin{array}{l}\text { - MODIS True color image. Band } 1 \text { (Red), } 4 \text { (Green), } 3 \text { (Blue). } \\
\text { Natural looking image of the land surface. } \\
\text { - Band } 7 \text { (Red), } 2 \text { (Green), } 1 \text { (Blue) combination. Water features } \\
\text { are highlighted. } \\
\text { - Band } 3 \text { (Red), } 6 \text { (Green), } 7 \text { (Blue) combination } \\
\text { - NDVI image - Shows greenness of the surface. }\end{array}$ \\
\hline Data access & Free through the internet (NASA Earth Images, 2014.) \\
\hline
\end{tabular}

The content producer must aware the appropriate Media GIS files sizes to download MODIS data. As an example, a TIFF image with $250 \mathrm{~m}$ spatial resolution may exceeds $80 \mathrm{MB}$ in file size and takes a substantial time to download if the network connection is slow.
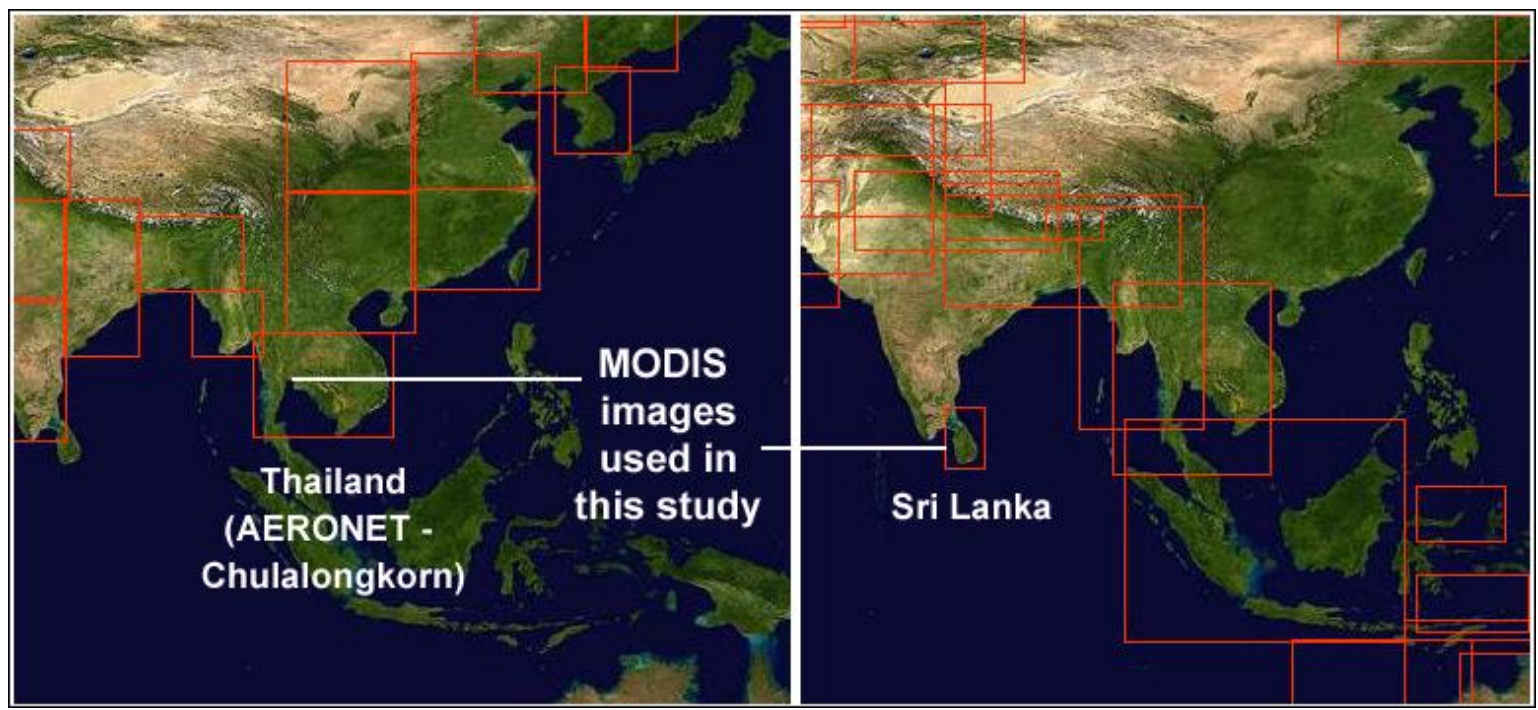

Figure 4. Geometrically and Radio metrically corrected MODIS image subsets cover most of the natural disaster-prone areas of the world (Base data Source: NASA Rapid Response, 2014) 


\subsection{METHODOLOGY}

\subsubsection{Image Processing}

The data processing routings to produce media content may be varied from producer to producer according to the level of skills in image processing and graphics. In this study, MODIS images of two case studies have converted into Media GIS contents using Photoshop CS4, ArcMap 10, and Google Earth software environment. The technical aspect of the production process is not lengthily discussed here to limit the length of the paper. MODIS images at $250 \mathrm{~m}$ spatial resolution have downloaded in Geo TIFF and KMZ formats (NASA Rapid Response, 2014). Tiff image is to use in graphic content and the corresponding $\mathrm{KMZ}$ file is to display the same Tiff image on Google Earth. In Photoshop, image file was clipped for the target area and added information according to the intended natural disaster Media GIS content. GIS information for this task can be collected from Google Earth high-

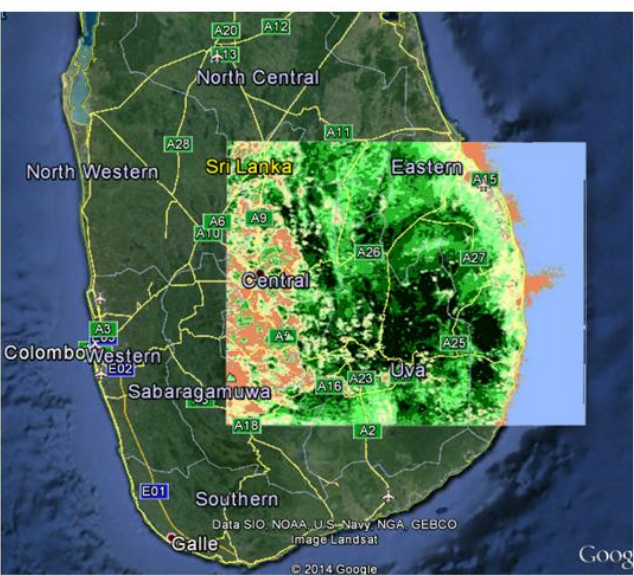

Figure 5. Extracting GIS data from Google Earth image (left) and adding image over the Google Earth and creating place marks using Google Earth functions (Base data Source: NASA \& Google Earth)

resolution images, by displaying the KMZ file on Google Earth. Generally, GIS data layers such as coastal line, major roads, and major cities are vital for any Media GIS content. In this study, target areas of both case studies were clipped in ArcMap and converted into KML (Keyhole Markup Language) format which can be displayed on Google Earth. GIS data extracted from Google Earth and graphical components such as text writing, arrows, polygons to show areas, and etc., were added in Photoshop. After the Photoshop editing, the image map is ready for WEB and print media applications. If the content intends to use on Google Earth for animated TV presentations, the image map needs to be registered on Google Earth environment. This can be done by few more image processing steps in ArcMap or, manually on the Google Earth using "add image" function. If the producer uses Google Image Pro, advance capabilities are available such as automatic import of GIS data on Google Earth (Google - Importing imagery, 2014).

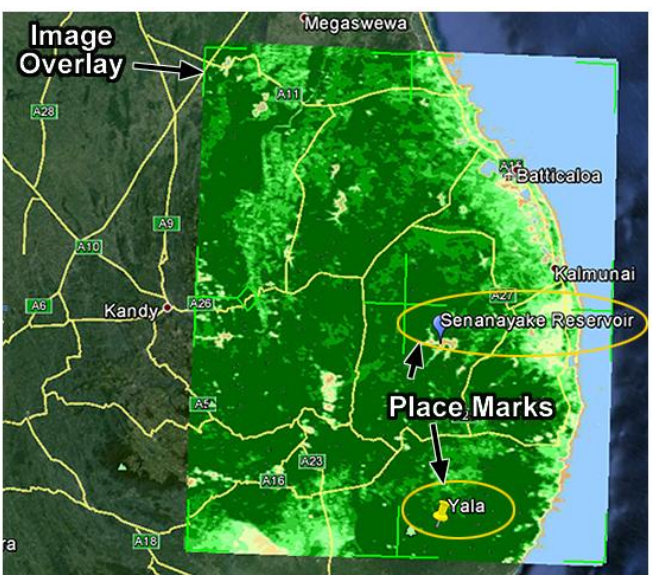




\subsubsection{Adding Images And Place Marks}

Media GIS content can be supported by the data available in Google Earth, when the initial area is displayed on Google earth using $\mathrm{KMZ}$ file format. Also, at various stages of the content production, Google Earth can be extensively used to enrich the content using freely available tools in Google Earth (figure 5). Once the original MODIS KMZ file displayed on the Google Earth, it's clipped and graphically enhanced image map can be overlaid on Google Earth. The clipped image needs to be manually adjusted to fit with the geography of the area. The produce can save this working image map in Google Earth environment as a $\mathrm{KMZ}$ file, which can be displayed separately.

\section{THE CASE STUDIES}

\subsection{Case Study 1 - Bangkok Floods, 2011}

The worst flood in last 50 years hit Bangkok city in Thailand during 2011 monsoon season. Bangkok and surrounding provinces were severely inundated by the long lasted flood. The disaster began around Jul 2011, and continued into Dec 2011 killing over 800 people. More than 13 million people were affected and the World Bank estimated the total damages as 45 billion USD as of Dec, 2011 (World Bank, 2011). The Media GIS contents were produced for 3 stages (figure 6, 7, and 8) of flood using MODIS band 7-2-1 combination. Full image scenes were downloaded to extract close-up image portions of Bangkok and vicinity. Also some GIS data layers (roads, administration boundaries) are presented in the image map (Media GIS content). All of these image maps can be opened in Google Earth to pinpoint the location in TV news programs or can be individually used in WEB and print media. With the semi-real-time presentation of these image maps in media, the public can gain a great deal of information on spatial conditions. The increase and decrease of flood extent is clearly standout in MODIS 7-2-1 images.

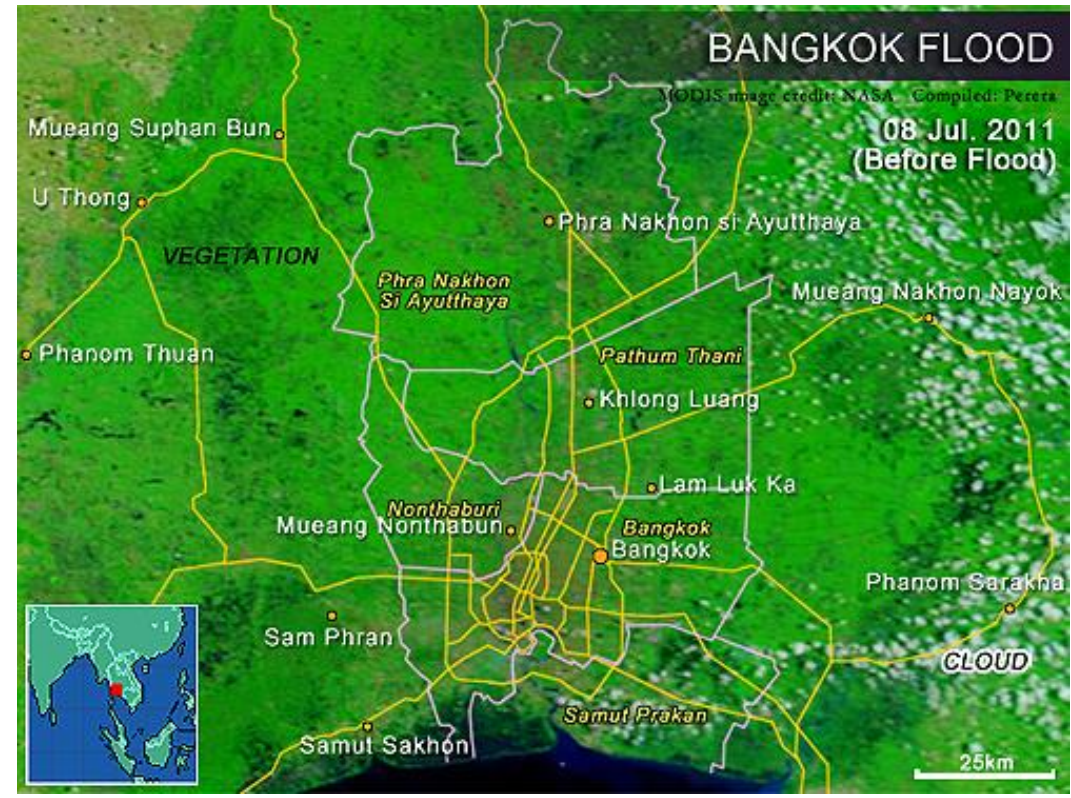

Figure 6. The before flood condition of Bangkok and vicinity with some GIS data 


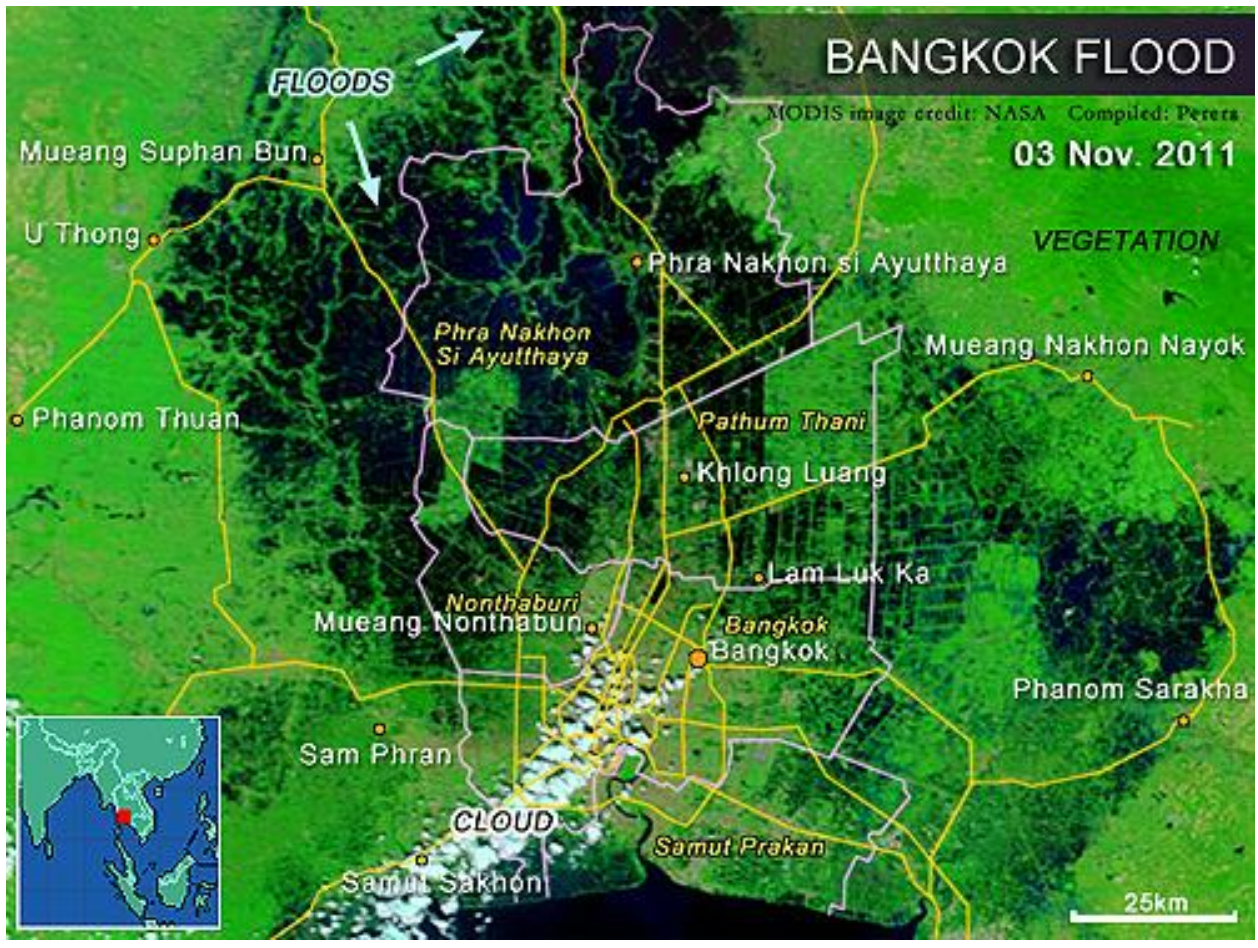

Figure 7. The flood peak, a large north and east to Bangkok city center is black or inundated

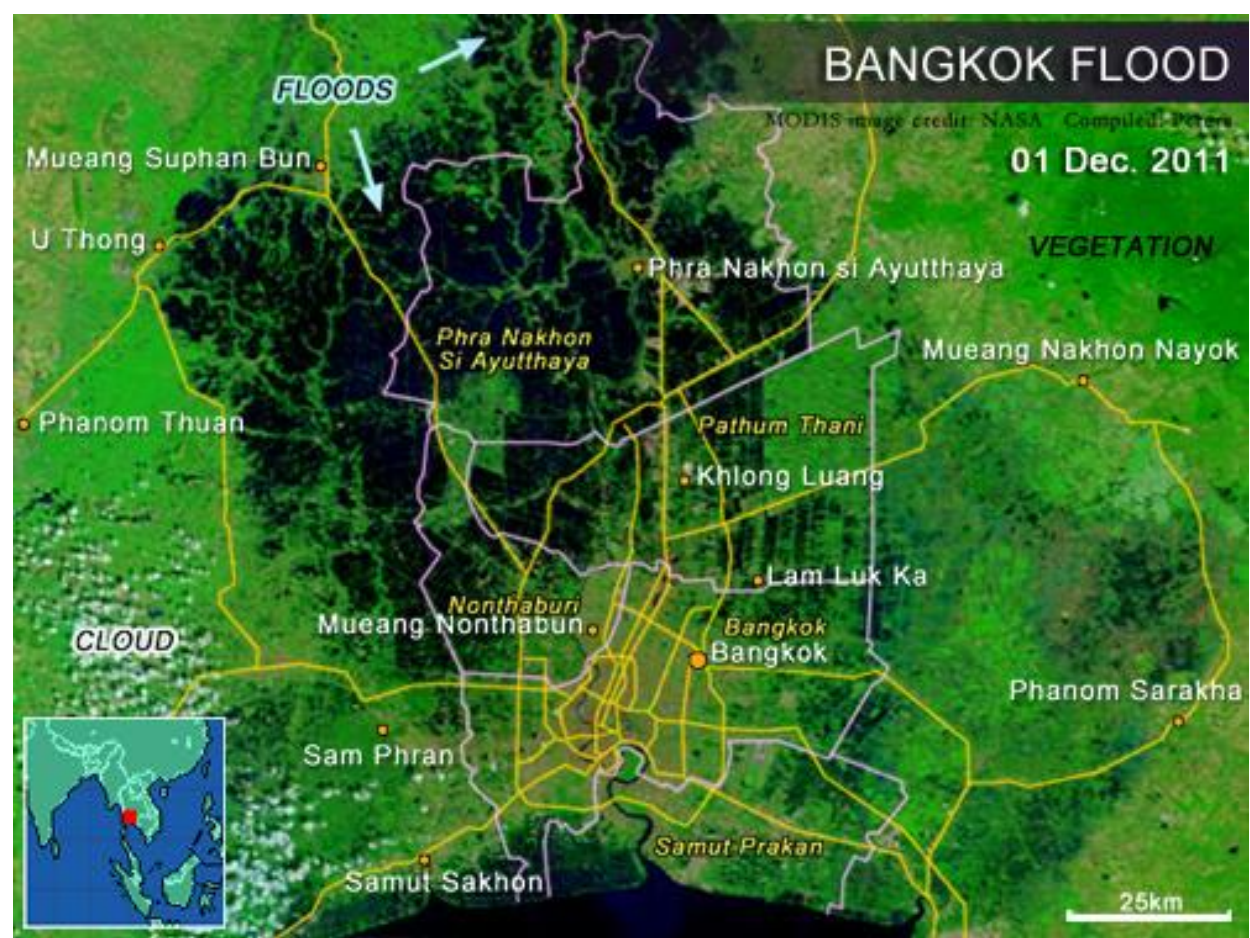

Figure 8. By Dec. 2011, flood started to decrease, however the satellite image shows a large area of northwest Bangkok is under water 


\section{2. Case Study 2 - Drought in Eastern Sri Lanka, 2014}

The prolong drought devastated northern and eastern regions of Sri Lanka in 2014, damaging farmlands and leaving people to depend on mobile drinking water supply. According to WFO records, about 768,000 people faced food insecurity and $18 \%$ of households recorded inadequate diets of low calorie (FAO, 2014). This long running natural disaster did not cause any deaths, but the village life and wildlife were severely affected. For this case study, MODIS NDVI (Normalized Difference Vegetation Index) images were used to compare normal conditions of eastern Sri Lanka with the drought-hit condition. NDVI is a by-product of satellite images; calculated using Red and Near-infrared bands (Weier and Herring, 2000). The higher values in NDVI pixels mean higher greenery, or vegetation is healthy. The high greenery in 2008 image (figure 9) indicates the healthy vegetation while same day image in 2014 shows how the drought has negatively affected by poor greener in the image. The content user (WEB, Newspaper, and TV) should be able to explain the story using this firsthand information to show the severity of the drought and its spatial distribution. Such an approach will help general public to get a quantitative and qualitative idea about the severity of the drought and the spatial character of affected areas.

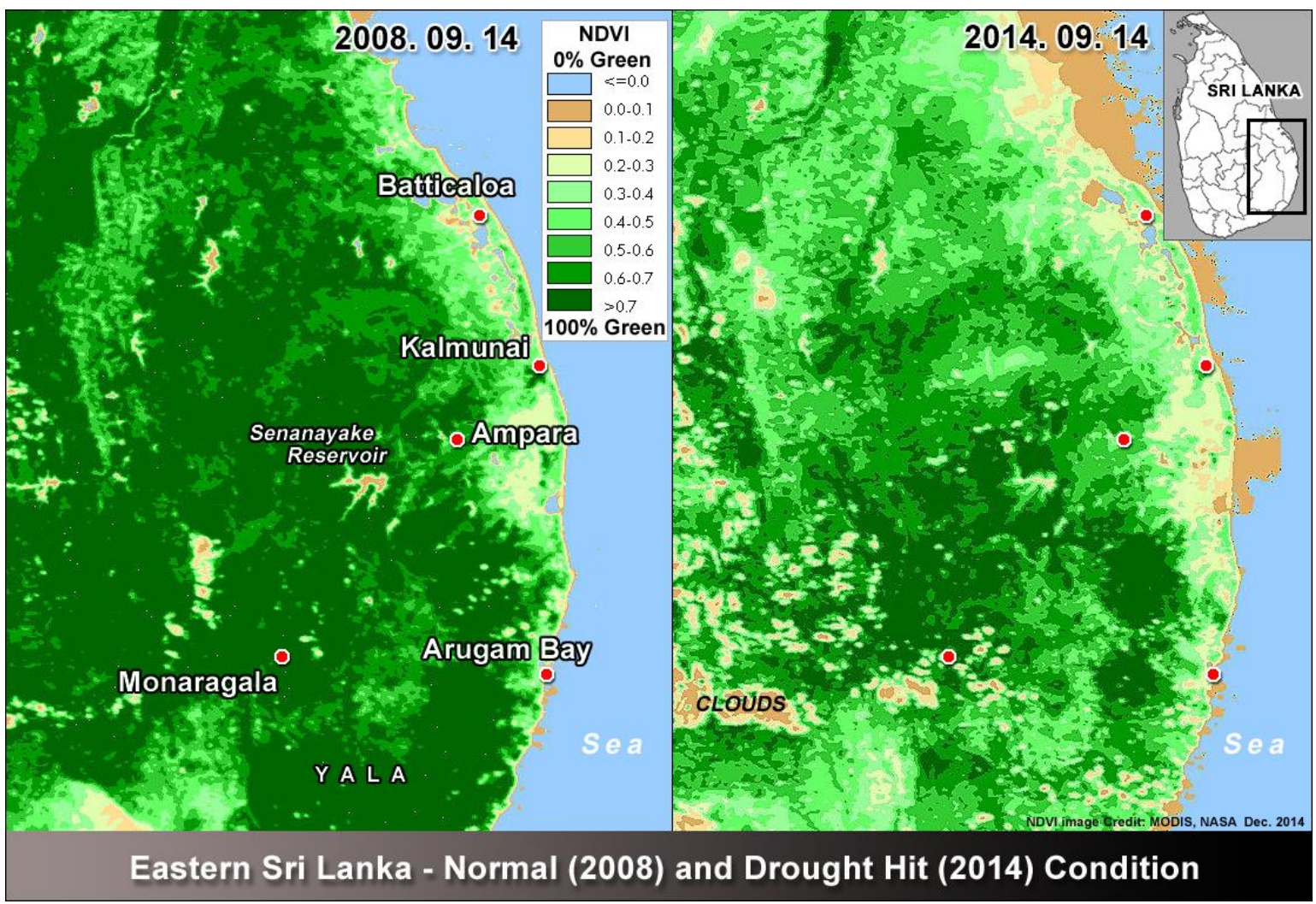

Figure 9. NDVI image has used to demonstrate the severity of drought in Eastern Sri Lanka 


\section{3. Mobile Contents}

The exact same media content can be re-produced for mobile media using a very little extra time on production. Mobile media demands graphic contents with small files size, which should be less than $100 \mathrm{k}$ to accommodate various capabilities in mobile phones. As Mobile Advertizing Guidelines explains, media contents may use the maximum image size of 320 pixels by 240 pixels which is the recommended size for large MMS (multimedia messaging service) video (Mobile marketing association, 2009). The Figure 10 shows the mobile media content reproduced from the figure 7 into $320 \times 240$ dimension and jpg image file is about $30 \mathrm{k}$ at $50 \%$ quality.

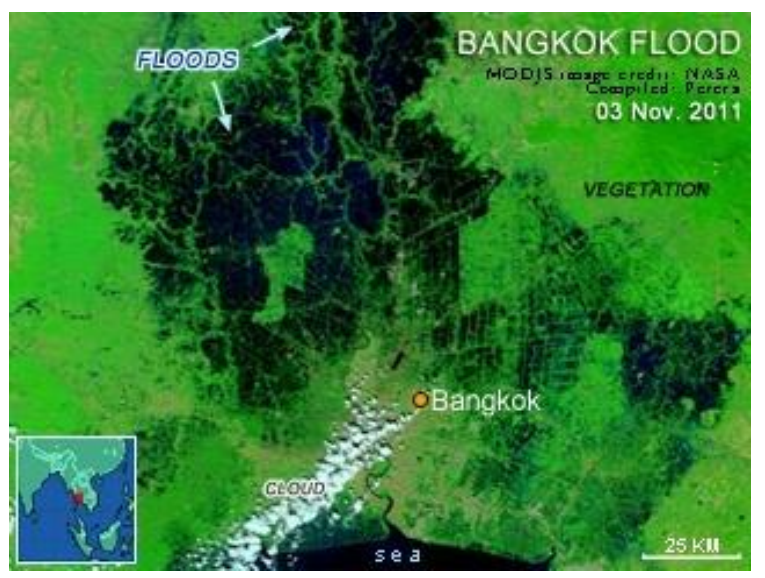

Figure 10. Re-production of the content for mobile media use

In commercial application, all these environmental disaster media contents can be used to enrich any news presentation and other weather and environment related programs and documents. The case study presented here only focused on production aspects of the media contents; hence, descriptive exploration of facts related to the spill was not discussed in length.

\section{RECENT TRENDS}

Due to the ever growing commercial competition, technologies related to the WWW are undergoing regular developments (Ostrow, 2007). Also, some of the latest developments in web based content production pay attention to the visual character of the content, such as visualizing words and visual web searching (Friedman, 2007). With the ever-growing speed of these developments in the media world, content production faces an endless challenge to meet new demands. These developments have influenced to introduce new modules in leading GIS software packages too. In the latest versions of Arc View, Arc Editor and Arc Info, the user (or content producer) can understand the geographic context of data, allowing identifying relationships and patterns in new ways (Arc View - overview 2010). From the other hand, powerful yet user friendly functions in Photoshop CS and other graphic provides rich tools to produce and manage graphic contents. Google Earth plays vital role in data exploring and presenting, by combining Media GIS products with location using the KML file format. GIS technology provides the base technology to integrate data files in a spatially accurate and academically sound manner (esri, 2010) to commercially produce media contents for natural disasters.

\section{CONCLUSIONS}

Freely available MODIS sensor images can be successfully used to produce "semi real time" Media GIS contents to display many natural disasters, specially, when the disaster has an impact on a wider region. Media GIS contents have to satisfy a number of requirements in the production process, such as optimization of esthetic quality and production 
speed, which is not the priority in conventional GIS and remote sensing studies. Yet, scientists have to guide content producers in this new application, since basics in spatial data visualization and accurately registered GIS data sets are important to set a reliable working culture. The case studies presented in this study demonstrate disaster information using firmly registered multi-temporal MODIS products. When the content is fresh, graphically attractive, and geographically accurate, viewers obtain a better understanding about the nature of the disaster which may increase the public involvements in disaster mitigation efforts.

\section{ACKNOWLEDGEMENTS}

Thanks are due to CEReS, Chiba University, Japan and Professor Kevin McDougal, University of Southern Queensland, Australia, for funding and institutional facilities provided for this work.

\section{REFERENCES}

ALTAN, O., BACKHAUS, R., BOCCARDO, P., ZLATANOVA, S. (2010). Geo information for Disaster and Risk Management, Examples and Best Practices Joint Board of Geospatial Information Societies 2010

ARCVIEW - OVERVIEW, (2010). http://www.esri.com/software/arcgis/arcvie w/index.html

ESRI (2010). GIS for Media and press, http://www.esri.com/industries/media/index. html

FAO (2014). https://www.wfp.org/countries/srilanka/publications/emergency-assessments

FRIEDL, M.A., MCIVER, D.K., HODGES, J.C.F., ZHANG, X.Y., ET AL., (2002). Global land cover mapping from MODIS: algorithms and early results. Remote Sens Environ 83, pp 287-302

FRIEDMAN, V. (2007). Data Visualization:

Modern Approaches,

http://www.smashingmagazine.com/2007/08

/02/data-visualization-modern-approaches/

GOOGLE - IMPORTING IMAGERY, (2014).

https://support.google.com/earth/answer/148

109 ?hl=en

GUMLEY, L., DESCLOITRE, J., SHMALTZ,

J.. CREATING, (2003). Reprojected True Color MODIS Images: A Tutorial. University of Wisconsin-Madison, 19 pages.

HALL, D.K., RIGGS, G.A., SALOMONSON, V.V., DIGIROLAMO, N.E., BAYR, K.J., (2002). MODIS snow cover products. Remote Sens. Environ. 83, pp.181-194

KRAAK, M., (1999). 'Visualising spatial distributions', in Geographical information systems, vol. 1, 2nd edn, John Wiley \& Sons, Canada, pp. 157-173.

MOBILE MARKETING ASSOCIATION, (2009). Mobile Advertizing Guidelines, Version 04.

http://www.mmaglobal.com/mobileadvertisi ng.pdf

MODIS WEB (2012).

http://modis.gsfc.nasa.gov/

NAKYA, S., RANGSIPANICH, A., KAEWSING, W. (2007). Applications of terra MODIS data for disaster monitoring in Thailand, Geo-Informatics and Space Technology Development Agency, Thailand.

NASA RAPID RESPONSE (2014). http://lance.nasa.gov/imagery/rapidresponse/

NASA EARTH IMAGES, (2014). http://lancemodis.eosdis.nasa.gov/imagery/subsets/?are $\mathrm{a}=\mathrm{sea}$ 
NATIONMASTER.COM (2010). Encyclopedia - Geographic information system http://www.statemaster.com/encyclopedia/G eographic-information-system

NEW WORLD ENCYCLOPEDIA (2008). mass media, http://www.newworldencyclopedia.org/entry /Mass_media

OSTROW, A. (2007). 16 Awesome Data Visualization Tools, http://mashable.com/2007/05/15/16awesome-data-visualization-tools/

PERERA, K. \& PATHIRANA, A., (2006). The role of MODIS data in visualizing flood disaster information for mass media. Asian Journal of Geoinformatics, 6 (3). ISSN 1513-6728

PERERA K., \& TATEISHI R. (2008). Semireal time media contents on haze hazard in Ganges River Basin, 14 ${ }^{\text {th }}$ CEReS International Symposium of Remote Sensing, Nov 2008

PERERA, K., \& TSUCHIYA, K., (2009). Experiment for mapping land cover and its change in south eastern Sri Lanka utilizing $250 \mathrm{~m}$ resolution MODIS, Advances in Space Research 43, pp. 1349-1355

SHORT, N. M. (2010). Remote Sensing Tutorials, Ecological Damage from Natural and Manmade Events Oil Spills, http://rst.gsfc.nasa.gov/Sect3/Sect3_6a.html

STROEHLEIN, A. (2010). Why the media prefer natural disasters?

http://www.alertnet.org/db/blogs/3159/2010/ 00/21-100650-1.htm

SULTAN, A, H. S. LIM, M. Z. MATJAFRI, K. ABDULLAH AND N., SALEH, (2008). Innovative satellite image map of R.Alkhabrta area, Saudi Arabia using high resolution image, The International Archives of the Photogrammetry, Remote Sensing and
Spatial Information Sciences. Vol. XXXVII. Part B7. Beijing

USGS GEOGRAPHY PUBLICATIONS (2008). Geographic Information Systems, http://edc2.usgs.gov/pubslists/gis_poster/ind ex.php

USGS, (2007). MODIS NDVI products, https://lpdaac.usgs.gov/lpdaac/products

USGS, (2011). Near Real-time Satellite Data Delivery for Natural Disasters, https://lpdaac.usgs.gov/user_community/dat a in action

WEIER, J. AND HERRING (D. 2000).

Measuring Vegetation (NDVI \& EVI), http://earthobservatory.nasa.gov/Features/M easuringVegetation/

WORLD BANK, (2011). The World Bank Supports Thailand's Post-Floods Recovery Effort

http://go.worldbank.org/TCFEHXJML0

ZHAN, X., SOHLBERG, R.A., TOWNSHEND, J.R, G., DIMICELI, C., CAROLL, M.L., EASTMAN, J.C., HANSEN, M.C., DEFRIES, R.S. (2002). Detection of land cover changes using MODIS 250 m data. Remote Sens. Environ. 83, pp. 336-350 